OPEN ACCESS

ISSN 2580-7730 (online)

Edited by:

Andika Aliviameita

Reviewed by:

Yos Adi Prakoso

${ }^{*}$ Correspondence:

Syahrul Ardiansyah syahrulardiansyah@umsida.ac.id

Received: 8 September 2020

Accepted: 19 November 2020

Published: 31 Desember 2020

Citation:

Zakaria $R$ and Ardiansyah S (2020)

Potential Analysis Of Toxoplasmosis

Distribution In Wild Cats (Felis

silvestris) In Some Markets Of

Sidoarjo District Through Microscopic

Identification Of Toxoplasma gondii

Medicra (Journal of Medical

Laboratory Science/Technology).

10.21070/medicra.v3i2.890

\section{Potential Analysis Of Toxoplasmosis Distribution In Wild Cats (Felis silvestris) In Some Markets Of Sidoarjo District Through Microscopic Identification Of Toxoplasma gondii}

\author{
Analisis Potensi Penyebaran Toksoplasmosis \\ Pada Kucing Liar (Felis silvestris) Di Beberapa \\ Pasar Kabupaten Sidoarjo Melalui Identifikasi \\ Toxoplasma gondii Secara Mikroskopis
}

Rizal Zakaria, Syahrul Ardiansyah*

Teknologi Laboratorium Medis, Fakultas IImu Kesehatan, Universitas Muhammadiyah Sidoarjo, Jl. Raya Rame Pilang No. 4 Wonoayu, Sidoarjo, 61261, Jawa Timur, Indonesia. Tel.: (031) 8962733

There are many diseases caused by parasitic infection, one of them is toxoplasmosis which is a zoonotic disease. This study was to determine the potential spread of wild cat toxoplasmosis in several markets. The sample used in this study were 24 stray cats taken from the Larangan market, Suko market and Sukodono market in Sidorajo district, using a method of determining the size of the sample based on incidental sampling. Sample were examined using the floating method.The prevalence result obtained from Larangan market $(37,5 \%)$, Suko market $(37,5 \%)$ and Sukodono market $(12,5 \%)$. Prevalence result in Larangan market and Suko market greater than in Sukodono market, this is due to environmental factors in Sukodono market cleaner and better sanitation. Human can become infected with oocyst if they consume food or inhale particle contaminated with T.gondii parasites. High number of cat with oocyst T.gondii can be caused by a dirty environment.

Keywords: market, oocyst, wild cat (Felis silvestris), Toxoplasma gondii, toxoplasmosis

Terdapat banyak penyakit yang disebabkan oleh infeksi parasit, salah satunya adalah toksoplasmosis yang merupakan penyakit zoonosis. Penelitian ini bertujuan mengetahui potensi penyebaran toksoplasmosis pada kucing liar di beberapa pasar. Sampel yang digunakan sebanyak 24 kucing liar yang diambil dari Pasar Larangan, Pasar Suko dan Pasar Sukodono di Kabupaten Sidoarjo, menggunakan metode penentuan besar sampel berdasarkan kebetulan (insidental sampling). Sampel diperiksa menggunakan mikroskop dengan metode apung. Didapatkan hasil prevalensi dari Pasar Larangan (37,5\%), Pasar Suko (37,5\%) dan Pasar Sukodono 
(12,5\%). Hasil prevalensi di Pasar Larangan dan Pasar Suko lebih besar dibandingkan Pasar Sukodono, hal tersebut disebabkan oleh faktor keadaan lingkungan di Pasar Sukodono yang lebih bersih serta sanitasi yang baik.Manusia dapat terinfeksi ookista jika mengkonsumsi makanan atau menghirup partikel yang terkontaminasi parasit T.gondii. Jumlah kucing terinfeksi ookista T.gondii di pasar yang tinggi dapat disebabkan oleh lingkungan yang kotor.

Kata Kunci: kucing liar, ookista, pasar, Toxoplasma gondii, toksoplasmosis 


\section{PENDAHULUAN}

Indonesia sebagai salah satu negara berkembang memiliki banyak permasalahan penyakit pada hewan maupun manusia, salah satunya adalah penyakit yang muncul di area tertentu dan tidak menyebar ke area lain dengan cepat atau endemik Iskandar (1999). Terdapat banyak penyakit yang disebabkan oleh infeksi parasit, salah satunya yaitu toksoplasmosis yang merupakan penyakit zoonis. Toksoplasmosis disebabkan oleh protozoa Toxoplasma gondii Subekti and Arasyid (2006). Gejala yang timbul diantaranya kejang-kejang, spasmus otot, abortus, opistotonus bahkan dapat menimbulkan paralisa oto-otot tubuh. Umumnya Pada manusia penyakit ini sering menginfeksi pada wanita serta ibu hamil namun pria juga dapat terinfeksi. Infeksi toksoplasmosis jika terjadi secara kongenital dapat menyebabkan bayi mengalami perkapuran, mikrosefalus, korioretinitis, gangguan psikologis, hidrosefalus, kejang- kejang serta pada anak setelah lahir akan menyebabkan gangguan mental. Sedangkan pada hewan, toxoplasma dapat menyebabkan kelainan kongenital, abortus, kematian dini, serta berpotensi menyebarkan pada manusia sehingga menimbulkan kerugian ekonomi Nurcahyo et al. (2011).

Kucing merupakan salah satu vektor dalam perkembangan dan penyebaran penyakit infeksi yang disebabkan oleh parasit Robson and Waugh (2011). Kedekatan kucing dengan manusia menjadi salah satu penyebab terjadinya penularan penyakit yang diderita kucing ke manusia maupun sebaliknya Sasmita (2006).

Menurut Riyanda (2017) seroprevalensi toksoplasmosis pada manusia di Indonesia berkisar antara 2\% - 63\% dan memiliki angka yang berbeda-beda pada setiap daerah. Sedangkan pada kucing di Surabaya angka prevalensi toksoplasmosis juga cukup tinggi, yaitu: $46,7 \%$ dari 30 kucing yang berasal dari beberapa rumah sakit dan $60 \%$ untuk kucing yang berasal dari pasar Sasmita (2006). Kucing merupakan salah satu hewan yang sangat dekat dengan manusia, kedekatan kucing dengan manusia terjadi di berbagai tempat, salah satunya di pasar.

Penelitian tentang toksoplasmosis pada kucing liar di Pasar Larangan, Pasar Suko dan Pasar Sukodono Kabupaten Sidoarjo belum pernah dilakukan sebelumnya. Analisis potensi penyebaran toksoplasmosis di beberapa Pasar Kabupaten Sidoarjo melalui identifikasi $T$. gondii secara mikroskopis diharapkan dapat menambah informasi dalam upaya pengendalian penularan $T$. gondii ke manusia.

\section{METODE}

Penelitian ini bersifat deskriptif analisis karena penelitian ini menggambarkan bagaimana potensi penyebaran toksoplasmosis pada kucing liar di Pasar Larangan, Pasar Suko dan Pasar Sukodono Kabupaten Sidoarjo.

Pengambilan sampel kucing liar menggunakan teknik incidental sampling, dimana kucing yang diambil merupakan kucing dewasa tanpa membedakan jenis kelamin. Pengambilan sampel dilakukan pada waktu pagi, siang dan sore. Pemilihan pengambilan waktu pagi, siang dan sore didasarkan pada jam keramaian dipasar.

Kucing liar dari Pasar Larangan, Pasar Suko dan Pasar Sukodono yang diambil dan dipelihara selama beberapa hari hingga kucing mengeluarkan feses, kemudian feses disimpan dalam pot plastik, kemudian dibawa ke laboratorium parasitologi.Timbang masing-masing feses sebanyak 2 gram di dalam beker glass. Ditambahkan aquades sebanyak $8 \mathrm{ml}$ kemudian diaduk hingga homogen lalu dipindahkan pada tabung sentrifus untuk disentrifugasi menggunakan kecepatan $1200 \mathrm{rpm}$ selama 3 menit. Supernatan dibuang kemudian menambahkan larutan garam $(\mathrm{NaCl})$ jenuh hingga $3 / 4$ volume tabung dan mengaduk hingga homogen. Larutan kemudian disentrifus kembali dan ditambahkan cairan pengapung secara perlahan menggunakan pipet pasteur hingga permukaan cairan cembung. Kemudian menunggu selama 1 2 menit supaya ookista naik ke permukaan. Siapkan cover glass kemudian ditempelkan pada permukaan cairan yang cembung dan ditempelkan pada objek glass dan diamati menggunakan mikroskop dengan perbesaran 40x10 Nurnaningsih (2017). Hasil pemeriksaan dinyatakan positif jika ditemukan ookista T.gondii pada sediaan feses kucing liar dan dinyatakan negatif apabila tidak terdapat ookista $T$. gondii pada sediaan feses kucing liar.

Data penelitian diambil berdasarkan teknik observasi langsung (pengamatan secara mikroskopis) terhadap feses kucing liar. Jumlah feses kucing positif (+) dan negatif (-) ookista T.gondii kemudian dicatat dan digunakan untuk mengetahui prevalensi T.gondii pada kucing liar dipasar.

\section{HASIL DAN PEMBAHASAN}

Hasil pemeriksaan 24 sampel feses kucing liar secara mikroskopis dengan menggunakan metode pengapungan ditemukan 7 sampel yang positif ookista T.gondii yaitu 3 dari Pasar Larangan, 3 dari Pasar Sukodan 1 dari Pasar Sukodono.

Tabel 1 menunjukkan dari 24 sampel kucing liar yang diperiksaterdapat 7 sampel (atau sebesar 29,2\%) feses kucing liar yang positif terinfeksi ookista T.gondii dan 17 sampel (atau sebesar 70,8\%) feses kucing tidak terinfeksi T.gondii (negatif). Hasil tersebut menunjukkan bahwa terdapat potensi penularan T.gondii pada kucing liar yang berada di Pasar Larangan, Pasar Suko dan Pasar Sukodono, yang memang pola hidup dan lingkungannya sangat berbeda dibandingkan dengan kucing ras maupun kucing kampung yang dipelihara dengan baik.

Gambar 1 menunjukan hasil prevalensi kucing terinfeksi toksoplasma, sedangkan Gambar 2 merupakan Ookista T.gondii pada pemeriksaan mikroskop perbesaran 40x10. Prevalensi kucing terinfeksi toksoplasma di pasar Sukodono sebesar $12,5 \%$, angka tersebut lebih kecil jika dibandingkan dengan prevalensi kucing terinfeksi toksoplasmadi Pasar Suko dan Pasar Larangan yang sebesar 37,5\%. Perbedaan 
prevalensi toksoplasmosis yang terjadi tersebut salah satunya disebabkan oleh karakteristik dan tingkat kebersihan.

Hasil pengamatan di Pasar Sukodono pada Tabel 1 menunjukkan terdapat 1 sampel positif T.gondii (12,5\%) dan 7 sampel negatif $(87,5 \%)$. Pasar Sukodono merupakan lokasi dengan peluang kucing terinfeksi T.gondii lebih kecil dibandingkan dengan pasar Larangan dan Pasar Suko. Pasar Sukodono merupakan pasar semi modern, hal tersebut dapat dilihat dari bangunan serta kebersihan lingkungan pasar. Sampel feses kucing positif ookista T.gondii bisa disebabkan oleh makanan maupun lingkungan tempat kucing tinggal. dilihat dari segi lingkugan dan sanitasi pasar Sukodono sudah sangat baik, hanya saja karena jumlah pedagang dan konsumen yang banyak serta ramai kerap kali membuat tempat pembuangan sampah di pasar ini penuh. Tempat sampah yang penuh dan lama tidak dibersihkan menjadi tempat untuk kucing dan tikus mencari makan.

Jumlah sampel dengan hasil negatif di pasar Sukodono lebih banyak dibandingkan dengan hasil positif. Sampel dengan hasil negatif bisa disebabkan pemberian makan $d r y$ food (pakan kucing kering berbentuk seperti biskuit) oleh para pedagang, serta kebersihan sanitasi dan pasar yang menyebabkan vektor parasit $T$.gondii jarang ditemui.

Hasil pemeriksaan sampel feses kucing dari Pasar Suko terdapat 3 sampel positif terinfeksi ookista T.gondii (37,5\%) dan 5 sampel negatif $(62,5 \%)$. Pasar Suko merupakan pasar tradisional yang lokasinya berdampingan langsung dengan sungai dan menjadi satu dengan pemukiman warga. Sampel feses yang positif terinfeksi ookista T.gondii dapat terjadi karena selain kondisi pasar yang kurang bersih, sanitasi dipasar ini juga kurang baik karena posisinya yang berada lebih rendah dari badan jalan. Warga yang berada disekitar pasar juga kurang menjaga kebersihan lingkungan tempat tinggal sehingga menjadi tempat kesukaan bagi tikus yang merupakan hospes T.gondii.

Hasil sampel feses kucing positif infeksi ookista T.gondii di Pasar Larangan pada Tabel 1 sebanyak $3(37,5 \%)$ dan hasil sampel negatif infeksi ookista T.gondii $5(62,5 \%)$. Sebagian besar kucing di pasar Larangan tinggal di bilik toko yang sudah tidak ditempati, kucing tersebut hidup liar dengan memakan tikus, makanan sisa dan sisa jeroan ayam para pedagang. Lingkungan pasar Larangan yang dekat dengan tempat pembuangan sampah dan sanitasi yang kurang baik menjadi tempat hidup bagi tikus yang berpotensi untuk meningkatkan kemungkinan kucing terinfeksi T.gondii.

Ookista yang ditemukan dalam penelitian ini belum bersporulasi, memiliki bentuk bulat lonjong, dinding yang jelas dan satu sporoblas. Pada penelitian yang dilakukan oleh Sihombing (2018) juga ditemukan ookista yang sama dengan penelitian ini. Ookista yang belum bersporulasi bersifat tidak infektif karena tidak mengandung sporozoit Diaz et al. (2016).
Ookista dikeluarkan bersama dengan feses kucing dalam waktu 1-2 minggu setelah terjadi infeksi primer. Proses sporulasi terjadi kurang lebih selama 1-5 hari, proses sporulasi tergantung pada kelembaban lingkungan, erasi dan temperatur. Setelah feses melalui proses sporulasi, ookista akan berkembang menjadi dua sporoblas yang didalamnya masing-masing terdapat sporokista. Masing-masing sporokista tersebut akan membelah diri lagi yang akan memnghasilkan 4 sporozoit. Sehingga di dalam 1 ookista terdapat 8 sporozoit. Ookista yang belum bersporulasi hanya mampu bertahan hidup selama 24 jam pada suhu $37^{\circ} \mathrm{C}-$ $50^{\circ} \mathrm{C}$. Dengan pendinginan pada suhu $-21^{\circ} \mathrm{C}$ pada ookista yang belum bersporulasi akan dapat bertahan hidup hingga 28 hari, sedangkan pada suhu $-6^{\circ} \mathrm{C}$ ookista ini mampu bertahan hingga 14 hari. Untuk ookista yang telah bersporulasi mampu bertahan hidup selama 306 hari pada suhu $37^{\circ} \mathrm{C}$ Nurcahyo (2019). Sampel feses kucing dalam penelitian ini diamati secara mikroskopis kurang dari 24 jam setelah feses dikeluarkan oleh kucing dan didapatkan hasil positif ookista yang ditemukan merupakan ookista yang belum bersporulasi.

Kucing sebagai inang definitif memegang peranan sangat penting dalam penyebaran toksoplasmosis Sasmita et al. (1993). Potensi penyebaran toksoplasmosis di Pasar Larangan, Pasar Suko dan Pasar Sukodono perlu mendapatkan perhatian, dikarenakan tingkat sampel positif infeksi ookista T.gondii yang cukup besar yaitu 29,2\%. Tingginya jumlah kucing yang terinfeksi ookista T.gondii menimbulkan suatu potensi penularan T.gondii terhadap manusia serta dapat memberikan dampak yang merugikan bagi manusia.

\section{KESIMPULAN}

Jumlah sampel feses kucing liar positif ookista T.gondii sebanyak 29,2\% (7 dari 24 sampel) dengan perbandingan prevalensi pada masing-masing pasar yaitu: Pasar Larangan $37,5 \%$, Pasar Suko 37,5\% dan Pasar Sukodono 12,5\%. Potensi terbesar penyebaran toksoplasmosis pada kucing liar berada di Pasar Suko dan Pasar Larangan.

\section{KONTRIBUSI PENULIS}

Penulis pertama berperan utama dalam pengumpulan data, sedangkan penulis kedua membantu dalam penyusunan artikel.

\section{PENDANAAN}

Dana penelitian berasal dari dana mandiri peneliti. 


\section{UCAPAN TERIMA KASIH}

Terimakasih kepada segenap pihak yang telah membantu dalam penelitian ini.

TABEL 1 / Hasil Pemeriksaan Sampel Feses Kucing Liar Secara Mikroskopis Di Pasar Larangan, Pasar Suko dan Pasar Sukodono, Kabupaten Sidoarjo

\begin{tabular}{cccc}
\hline Kode Sample & P. Larangan & P. Suko & Hasil \\
1 & $(-)$ negatif & $(-)$ negatif & P. Sukodono \\
2 & $(-)$ negatif & $(+)$ positif & $(-)$ negatif \\
3 & $(+)$ positif & $(-)$ negatif & $(-)$ negatif \\
4 & $(-)$ negatif & $(+)$ positif & $(-)$ positif \\
5 & $(-)$ negatif & $(+)$ positif & $(-)$ negatif \\
6 & $(-)$ negatif & $(-)$ negatif & $(-)$ negatif \\
7 & $(+)$ positif & $(-)$ negatif & $(-)$ negatif \\
8 & $(+)$ positif & $(-)$ negatif & $(-)$ negatif \\
Jumlah Positif & $3(37,5 \%)$ & $3(37,5 \%)$ & $1(12,5 \%)$ \\
Jumlah Negatif & $5(62,5 \%)$ & $5(62,5 \%)$ & $7(87,5 \%)$ \\
Total & 8 & 8 & 8 \\
\hline
\end{tabular}



GAMBAR 1 / Grafik Hasil Pemeriksaan Sampel Feses Kucing Liar Secara Mikroskopis Di Pasar Larangan, Pasar Suko Dan Pasar Sukodono, Kabupaten Sidoarjo

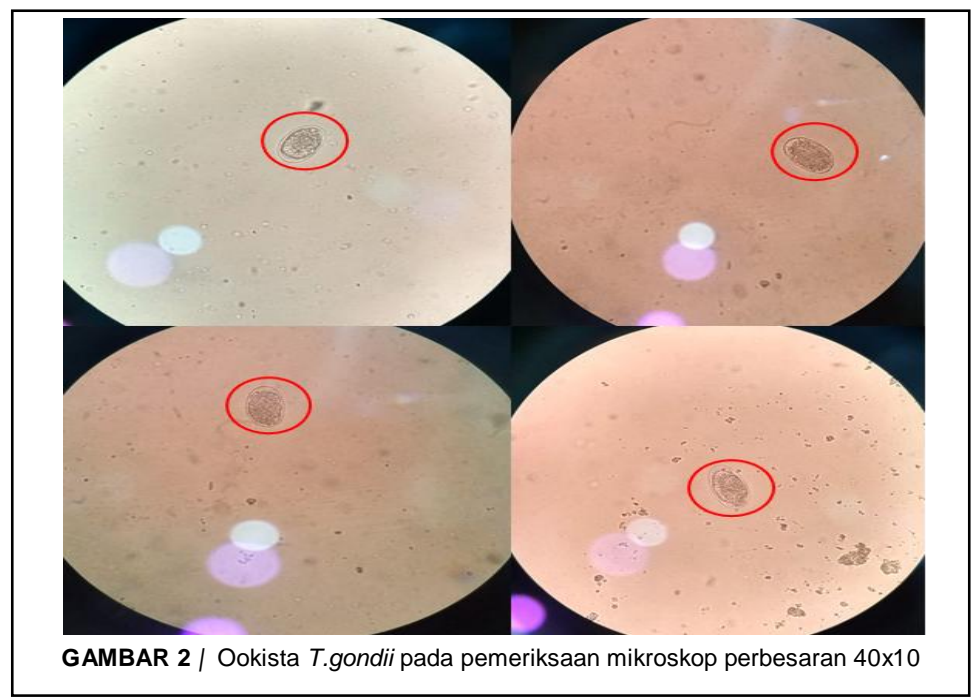




\section{REFERENSI}

Diaz, R., Harlia, E., \& Kurnani, T. B. A. (2017). Identifikasi protozoa pada digester tipe batch berbahan baku feses sapi potong dan batubara. Students $\begin{array}{llll}e \text {-journal. } & 6(1) . & 1-10 & \text { Retrieved }\end{array}$ http://jurnal.unpad.ac.id/ejournal/article/view/10940/4900

Iskandar, T. (1999). Tinjauan tentang toksoplasmosis pada hewan dan manusia. Wartazoa, 8(2), 59-63. Retrieved from http://medpub. litbang.pertanian.Go.id/index.php/wartazoa/article/download/734/743

Nurcahyo, W., Prastowo, J., \& Sahara, A. (2011). Toxoplasmosis prevalence in sheep in Daerah Istimewa Yogyakarta. Animal production, 13(2), 122-130. Retrieved from https://www.researchgate.net/publication/265079216.

Nurcahyo, W., \& Priyowidodo, D. (2019). Toksoplasmosis Pada Hewan. Yogyakarta: Samudra Biru

Nurnaningsih, M. (2017). Identifikasi Toxoplasma gondii pada feses kucing peliharaan. Karya Ilmiah. Analis Kesehatan Sekolah Tinggi Ilmu Kesehatan Insan Cendekia Medika. Jombang.

Riyanda, A. P. P. (2017). Seroprevalensi Toxo plasma gondii pada hewan ternak kambing di kota Bandar Lampung. Skripsi. Fakultas Kedokteran Universitas Lampung. Lampung.

Robson, S. E., \& Waugh, J. (2011). Patologi pada kehamilan: manajemen \& asuhan kebidanan. Jakarta: EGC.

Sasmita, R. and Suprihati, E. (1993). Isolasi kista Toxoplasma gondii dari otak kucing di pasar dan rumah sakit Kotamadya Surabaya. Bulletin IPKHI. $3(1), 2-10$.

Sasmita, R. (2006). Toksoplasmosis penyebab keguguran dan kelainan bayi. Surabaya: Airlangga University press.

Sihombing, W. S. (2018). Identifikasi oosista Toxoplasma gondii pada tinja kucing di desa Rawang Pasar VI Kabupaten Asahan. Karya Ilmiah. Analis kesehatan Poltekes Kemenkes Medan. Medan.

Subekti, D. T., \& Arsyid, N. K. (2006). Imunopatogenesis Toxoplasma gondii berdasarkan perbedaan galur. Immunopathogenecity, 16(3), 128-145. Retrieved from http://medpub.litbang.Pertanian.go.id/index.php

Conflict of Interest Statement: The authors declare that the research was conducted in the absence of any commercial or financial relationships that could be construed as a potential conflict of interest.

Copyright (C) 2020 Zakaria and Ardiansyah. This is an open-access article distributed under the terms of the Creative Commons Attribution License (CC $\mathrm{BY})$. The use, dis- tribution or reproduction in other forums is permitted, provided the original author(s) and the copyright owner(s) are credited and that the original publication in this jour- nal is cited, in accordance with accepted academic practice. No use, distribution or reproduction is permitted which does not comply with these terms. 